\title{
Mechanical and Surface Properties of Initial and Working Aesthetic Orthodontic Archwires
}

\author{
Tang YC ${ }^{1}$, Peh $\mathrm{XL}^{1}$, Zakaria NN², Radzi $\mathrm{Z}^{2^{*}}$ \\ ${ }^{1}$ Faculty of Dentistry, University of Malaya, Kuala Lumpur, Malaysia. \\ ${ }^{2}$ Department of Paediatric Dentistry and Orthodontics, Faculty of Dentistry, University of Malaya, Kuala \\ Lumpur, Malaysia.
}

\begin{abstract}
The study aimed to compare mechanical properties and surface characteristics of initial and working aesthetic archwires with their conventional counterparts. High Aesthetic Sentalloy (full rhodium coating nickel-titanium; Dentsply GAC) represented the initial aesthetic archwires; and FLI TRU-CHROME (labial PTFE-coated stainless steel; RMO) as the working aesthetic archwires; together with their conventional counterparts were analysed. A three point bending test was conducted using a universal testing machine (AGS-X SERIES, Shimadzu, Japan) to determine the load-deflection characteristics of archwires. Surface hardness was evaluated by Vickers microhardness test (HMV-FA, Shimadzu, Japan). A 3D Optical Surface Texture Analyzer (ALICONA, InfiniteFocus Real3D, Belgium) and a Field Emission Scanning Electron Microscope (FESEM, FEI Quanta 250, USA) were used for surface evaluation. Results showed that loaddeflection characteristics of High Aesthetic Sentalloy archwires did not differ from its control, whereas FLI TRU-CHROME archwires exhibited higher loading and unloading forces than its counterpart. No statistically significant difference in surface hardness was found between FLI TRU-CHROME and its control archwires. The coating surfaces of both aesthetic archwires were rougher than the non-coated conventional archwires, with similar roughness between non-coated surface of FLI TRU-CHROME archwires and its counterpart. FLI TRU-CHROME archwires showed a distinct coating thickness but coating layer is undefined in High Aesthetic Sentalloy archwires. In conclusion, the aesthetic rhodium coated nickel titanium archwire has similar mechanical properties as control nickel titanium archwire without being adversely affected by the addition of the coating layer. The aesthetic coated PTFE stainless steel archwire has higher load response which could be an advantage as rigid wire in working stage of orthodontic treatment. Based on their performance, their use could be recommended in cases where aesthetic aspect is crucial and where the friction aspect is not critical as their surface roughness values increased.
\end{abstract}

Keywords: Nickel/chemistry, Orthodontic Wires, Polytetrafluoroethylene/chemistry, Rhodium/chemistry, Stainless steel/chemistry, Titanium/chemistry

\section{INTRODUCTION}

Standard fixed orthodontic appliances consist of brackets, bands, elastomeric materials and archwires. The interaction between bracket and archwire is crucial in producing the optimal biomechanical forces for sliding tooth movement during orthodontic treatment (1). The archwire can be made from metal alloys such as stainless steel, nickel-titanium (NiTi), beta-titanium or polymer and composite fibers (2). Throughout the years, there has been an increasing demand 
of aesthetic orthodontic treatment. Many attempts have been made to improve aesthetic brackets. It is highly desirable that aesthetic archwires complement aesthetic brackets to enhance the appearance of patients during fixed orthodontic treatment. However, there is lack of practical data that can guide the clinician in using the aesthetic wires throughout the treatment.

The selection of archwire is mainly based on the purpose of treatment, which varies according to different stages of orthodontic treatment. Hence, there is no single ideal archwire that suits all treatment needs. There are three main phases in fixed orthodontic treatment namely (a) initial alignment phase, (b) working phase, and (c) retention and detailing phase (3). Among the important physical properties of the archwire are springback, stiffness, resilience, range and strength $(3,4)$. An archwire with springback has the ability in returning to its original shape and position after force application. The stiffness of archwires are usually related to the diameter of an archwire while the resilience is related to the capacity of energy stored after bending of wires. On the other hand, range is the maximum deflection of wire measured within its elastic limit and strength is the maximum force that is measured while the wire is at its maximum elastic range $(3,4)$. In order for teeth alignment to be effective at the initial stage of orthodontic treatment, the wires should present with minimum stiffness and maximum range where tooth displacement will be at its greatest. This will facilitate tooth movement in a low and constant force which is suitable for straightening and aligning of teeth in the early stage (5). Hence, nickel titanium round wires with their superelastic and flexible properties are preferred for initial phase (3). This is then followed by working archwires where stiffness is increased. In retention and detailing stage, high stiffness and low range rectangular wires are chosen $(3,6)$. The tight fit of rectangular wires against bracket slots provides a more precise three dimensional control of teeth. This suits the purpose of end stage treatment where teeth are retained at their corrected position (6). In addition, optical properties is becoming more important in producing an aesthetic archwire.

Types of aesthetic archwires include coated metal, and transparent non-metallic (7). Coating examples are either tooth coloured: polytetrafluoroethylene (PTFE), epoxy-resin, or metal coloured: rhodium implantation. One of the recognised drawback of aesthetic coating includes changes to the surface texture and topography. This in turn might cause friction and dimension variation $(8,9)$. Dimensional changes include either increasing thickness of wire as a whole or reducing central alloy core to accommodate the coating layer (10). PTFE, is a polymer consisting of carbon and fluorine and is better known as Teflon. In order for PTFE to be coated, purpose-cleaned compressed air transports the atomized particles to the substrate and placed in a chamber furnace for heat treatment. PTFE is widely accepted in clinical use due to its nonreactive, heat-resistant and hydrophobic properties. In order to ensure that the aesthetic wire did not cause any unwanted effect on the sliding mechanics, Rocky Mountain Orthodontics introduced labial-coated PTFE layer on Stainless Steel Rectangular wires (7). At the same time, DENTSPLY GAC introduced rhodium coated round $\mathrm{NiTi}$ archwires. The manufacturer claims that it gives a soft and frosted appearance, due to its low reflectivity in addition to its low friction and superelastic properties (11). The summary of the compositions and mechanical properties of the archwires are given in Table 1.

Table 1: The summary of the compositions and mechanical properties of the nickel titanium and stainless steel archwires (12).

\begin{tabular}{|c|c|c|c|c|}
\hline Type of wire & Typical Composition & $\begin{array}{l}\text { Modulus of Elasticity } \\
(\mathrm{GPa})\end{array}$ & $\begin{array}{l}\text { Yield Strength } \\
(\mathrm{MPa})\end{array}$ & Springback \\
\hline Nickel Titanium & $\begin{array}{l}55 \% \mathrm{Ni}, 45 \% \mathrm{Ti} \\
\text { (approx. and may contain } \\
\text { small amounts of } \mathrm{Cu} \text { or other } \\
\text { elements }\end{array}$ & 34 & $210-410$ & $0.0058-0.016$ \\
\hline $\begin{array}{l}\text { Stainless steel } \\
\text { (Austenitic) }\end{array}$ & $\begin{array}{l}17-20 \% \mathrm{Cr}, 8-12 \% \mathrm{Ni}, 0.15 \% \\
\mathrm{C} \text { (max), balance mainly } \mathrm{Fe}\end{array}$ & $160-180$ & $1100-1500$ & $\begin{array}{l}0.0065-0.0099(\text { Heat } \\
\text { treated) }\end{array}$ \\
\hline
\end{tabular}

Currently, there are several new aesthetic archwires introduced into clinical practice and there has been no published literature regarding the usage of aesthetic wires in full range orthodontic treatment (initial and working phase). In our study, we compare initial (High Aesthetic Sentalloy, full rhodium coated nickel-titanium; Dentsply GAC) and working (FLI TRU-CHROME, labial PTFE coated stainless steel; 
$\mathrm{RMO}$ ) aesthetic archwires with their conventional counterparts.

The null hypotheses are there are no difference in mechanical properties between aesthetic and conventional initial and working archwires and that their surface characteristics are similar.

Therefore, the objectives of our study were:

1. To test aesthetic initial archwires on the mechanical properties as compared to its conventional counterpart.

2. To test aesthetic working archwires on the mechanical properties as compared to its conventional counterpart.

3. To analyse the surface characteristics of archwires.

\section{MATERIALS AND METHODS \\ Materials}

The Rhodium coated nickel-titanium round archwire is chosen for initial archwire due to the manufacturing process that is able to produce thin coating layer which may not influence the properties of the inner nickel titanium core wire that is crucial for initial stage of the orthodontic treatment. In addition, it consisted of full rhodium coating on both anterior and posterior portion.

The labial PTFE coated stainless steel archwire was chosen as it has the coating on the labial surface for aesthetic purpose and maintaining the other three surfaces to slide freely in the bracket slot without causing any additional friction, which is crucial for working stage of the orthodontic treatment. Furthermore, additional of one coating layer did not alter the total cross sectional area of the core wire as much as full four coating layers and is practical for clinical use.

The details of four different groups of archwires used are summarized in Table 2. A total of 120 wire segments $(n=30)$ were prepared by cutting the straightest portion of the wires to approximately 20 $\mathrm{mm}$ in length using distal end cutter (Dentaurum, Germany). Each type of wires were evaluated for the following: (i) load deflection characteristics, (ii) indentation hardness, and (iii) surface characteristics (roughness and surface topography).

Table 2: Description of studied archwires

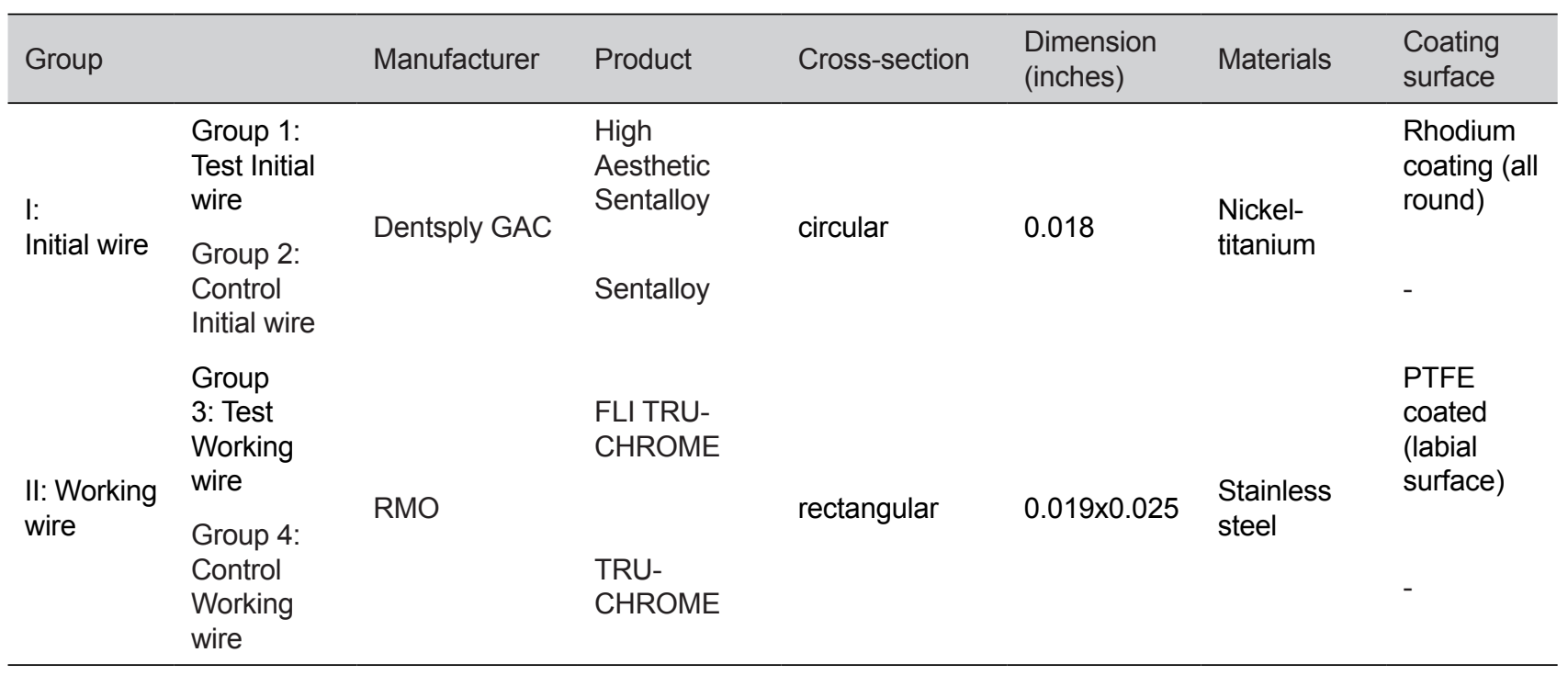

\section{(i) Load deflection characteristics}

Three point bending test provides the values for the modulus of elasticity in bending and the flexural stress-strain response of the materials. The test method involves a specified fixture on a universal testing machine. The sample is place on two supporting pins at a set distance apart and a third loading pin is lowered from above at a constant rate $(13,14)$. As the cross sectional shapes affect the test results, comparison can only be made between the groups of similar cross sectional shape.

In this study, the three-point bending tests were carried out using a Universal Testing Machine (AGS-X, Shimadzu, Japan) to evaluate the load deflection characteristics of archwires. The machine was set with a crosshead speed of $1 \mathrm{~mm} / \mathrm{min}$ using 50 $\mathrm{kN}$ load cell at room temperature. The specimen wire with a span of $20 \mathrm{~mm}$ was placed centrally on top of 
two poles, measured $14 \mathrm{~mm}$ apart on a stage (Figure 1). The middle portion of the wire was deflected to a maximum of $2 \mathrm{~mm}$ and then deactivated. A loaddeflection curve was analyzed using Trapezium Lite $X$ (Shimadzu, Japan) software. The load values were determined at 0.5, 1.0, $2.0 \mathrm{~mm}$ loading and 0.5 $\mathrm{mm}$ unloading. End displacement point was used to determine the presence of permanent deformity after bending.

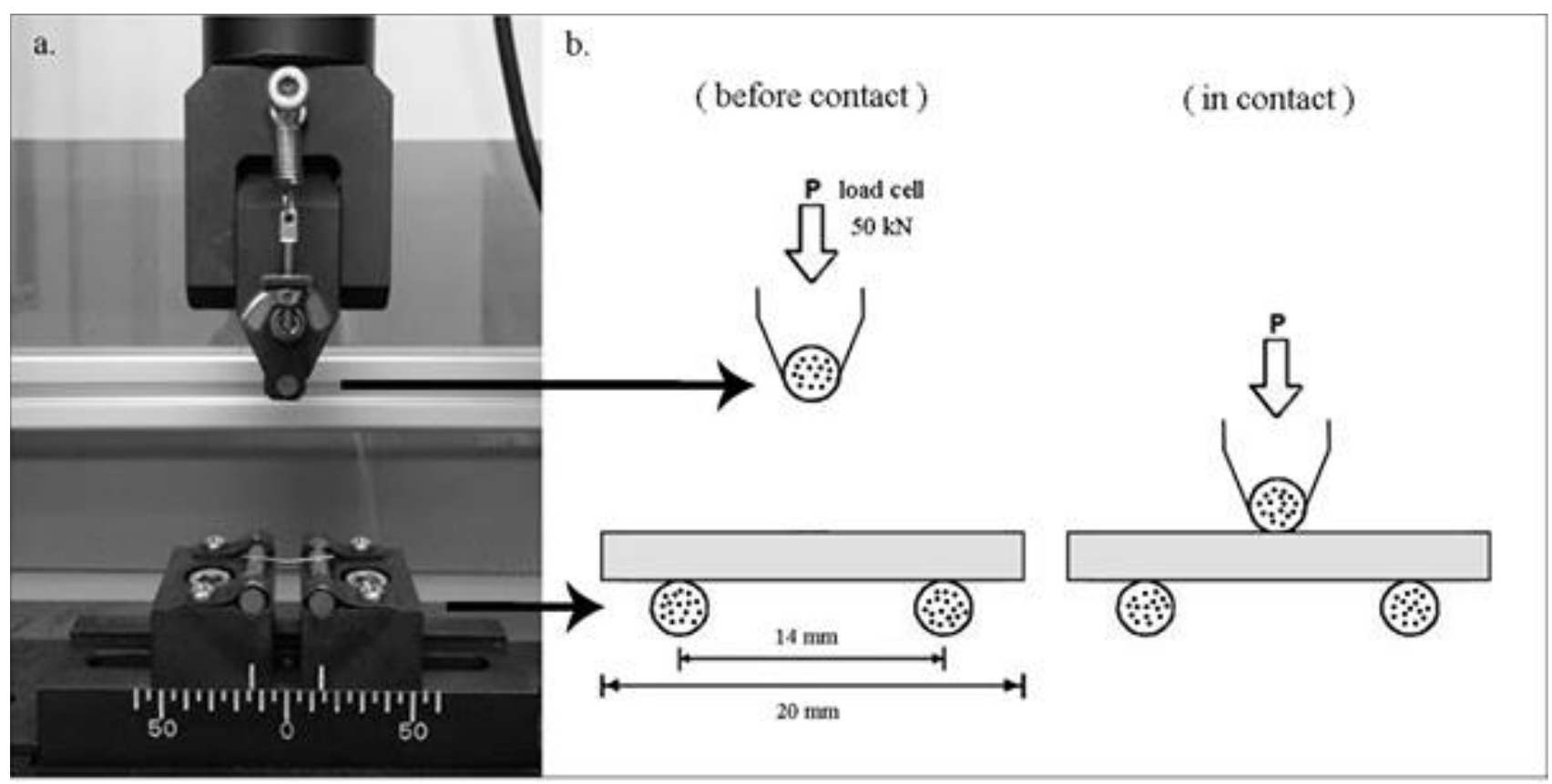

Figure 1: (a) Setup for three-point bend test. Distance between two poles was measured at $14 \mathrm{~mm}$ apart using the scale provided. (b) Diagram showing bending of archwire before contact and in contact. Wires were deflected to a maximum of 2 $\mathrm{mm}$ downwards.

\section{(ii) Indentation hardness}

Microhardness tests were carried out using Vickers microhardness tester (HMV-FA, Shimadzu, Japan) to evaluate hardness of Group II working archwire non-coated surfaces $(n=10)$. The archwire segment was held firmly onto the specimen table using BluTack (Bostik, Australia). The indentation test was conducted using a square-based pyramidal diamond indenter with a test load of 0.05 HV for 15 seconds. Indentation hardness was calculated using the formula based on the area of indentation, optical measurement system, shape factor of indenter, and the test load.

\section{(iii) Surface characteristics}

A 3D Optical Surface Texture Analyzer (ALICONA, InfiniteFocus Real3D, Belgium) was used to determine average surface roughness $(\mathrm{Ra})$ of specimen $(n=10)$. Five surfaces were analyzed, namely: top surface of all wires and labial surface of FLI TRU CHROME. The surface characteristic for
Group I was measured using $25 \mu \mathrm{m}$ Lambda C filter while an $80 \mu \mathrm{m}$ Lambda $C$ filter was used for group II samples.

A Field Emission Scanning Electron Microscope (FESEM, FEI Quanta 250, USA) was used to produce SEM images of cutting cross section; top and labial surfaces before and after three-point bending test, at different magnifications (200x, 250x and 1000x).

SEM images were used to compare the cross section dimension of archwires. The ratio of the surface area between coated and uncoated archwires was calculated using the following expression:

\section{Group I}

$$
\mathrm{R}=\frac{\Pi \mathrm{r}_{1}{ }^{2}}{\Pi \mathrm{r}_{2}{ }^{2}}-(1)
$$




\section{Group II}

$$
R={\frac{Y_{1} X_{1}}{Y_{2} X_{2}}}^{-(2)}
$$

Where,

Group I: $r_{1}$ is the radius of High Aesthetic Sentalloy and $r_{2}$ is the radius of Sentalloy, and

Group II: $\mathrm{X}_{1}$ is the width of FLI TRU-CHROME; $\mathrm{X}_{2}$ is the width of TRU-CHROME and $Y_{1}$ is the height of FLI TRU-CHROME archwire and $Y_{2}$ is the height of TRU-CHROME archwire from SEM images. If there is no changes in dimension between the coated and uncoated archwires, $R$ will be equal to 1 .

\section{Statistical Analysis}

The data obtained were analyzed using Statistical Package for the Social Science (SPSS V12.0.1, IBM, USA). The data were examined for the normality distribution with the Shapiro-Wilk test and the equality of variances with the Levene test. Descriptive data were expressed as median [ \pm Interquartile range (IQR)]. Numeric values were compared with independent t-test and nonparametric Kruskal-Wallis Test and Mann-Whitney $\mathrm{U}$ test was applied to data set that did not meet the criteria for parametric analysis.

\section{RESULTS}

\section{(i) Load deflection}

\section{Group I: GAC Sentalloy and GAC High Aesthetic Sentalloy (NiTi)}

The median and interquartile range for group I aesthetic and conventional archwires are tabulated in Table 3. Mann-Whitney test showed that there was no significant difference between aesthetic and conventional groups in all loading forces: $0.5 \mathrm{~mm}$ $(\mathrm{U}=25.00, \mathrm{Z}=-1.891)$; $1.0 \mathrm{~mm}(\mathrm{U}=27.00, \mathrm{Z}=-1.741)$; $2.0 \mathrm{~mm}(U=31.50, Z=-1.400)$. Similarly, there was no significant difference in unloading force: $0.5 \mathrm{~mm}$ $(U=38.00, \quad Z=-0.907)$ between aesthetic and conventional groups. The graph revealed all the end displacement points returned to zero.

\section{Group II: RMO TRU-CHROME and RMO FLI TRU- CHROME (Stainless Steel)}

The median and interquartile range for TRUCHROME (control) and its aesthetic counterpart were tabulated in Table 3. Mann-Whitney test showed that the load deflection behaviour of $R M O$ FLI TRU-CHROME (test aesthetic) and RMO TRUCHROME (control) wires are statistically significant in all forces: Loading $0.5 \mathrm{~mm}(U=9.00, Z=-3.10)$; Loading $1.0 \mathrm{~mm}(\mathrm{U}=0.00, \mathrm{Z}=-3.78)$; Loading $2.0 \mathrm{~mm}$ $(U=0.00, Z=-3.78)$; Unloading $0.5 \mathrm{~mm}(U=0.00, Z=-$ 3.78). There was a statistically significant difference

Table 3: Median (N) load values and interquartile range of aesthetic and conventional archwires in Group I: GAC High Aesthetic Sentalloy and GAC Sentalloy (NiTi) and Group II: RMO FLI TRU-CHROME and RMO TRU-CHROME

(Stainless Steel)

\begin{tabular}{|c|c|c|c|}
\hline \multirow[t]{2}{*}{ Sample } & Aesthetic & Conventional & \multirow[t]{2}{*}{ Asymp. Sig 2- tailed } \\
\hline & \multicolumn{2}{|c|}{ Median (N)(IQR) } & \\
\hline \multicolumn{4}{|l|}{ Group I } \\
\hline \multicolumn{4}{|l|}{ Loading } \\
\hline $0.5 \mathrm{~mm}$ & 1.1705 (0.081) & $1.1200(0.027)$ & 0.059 \\
\hline $1.0 \mathrm{~mm}$ & 1.7955 (0.049) & $1.8550(0.119)$ & 0.082 \\
\hline $2.0 \mathrm{~mm}$ & $2.0075(0.053)$ & $2.0460(0.111)$ & 0.162 \\
\hline \multicolumn{4}{|l|}{ Unloading } \\
\hline $0.5 \mathrm{~mm}$ & $1.1190(0.055)$ & $1.1525(0.149)$ & 0.364 \\
\hline \multicolumn{4}{|l|}{ Group II } \\
\hline \multicolumn{4}{|l|}{ Loading } \\
\hline $0.5 \mathrm{~mm}$ & $0.7685(0.031)$ & $0.8665(0.028)$ & $0.002^{*}$ \\
\hline $1.0 \mathrm{~mm}$ & $17.8785(0.951)$ & $16.6620(0.230)$ & $0.000^{*}$ \\
\hline $2.0 \mathrm{~mm}$ & $22.8755(0.966)$ & $22.2140(0.340)$ & $0.000^{*}$ \\
\hline \multicolumn{4}{|l|}{ Unloading } \\
\hline $0.5 \mathrm{~mm}$ & $11.6970(0.366)$ & $10.5675(0.346)$ & $0.000^{*}$ \\
\hline
\end{tabular}


in end displacement point values between FLI TRUCHROME (Mdn $=0.7685 \mathrm{~mm} I Q R=0.031)$ and TRUCHROME wires, $(\mathrm{Mdn}=0.8665 \mathrm{~mm}, \mathrm{IQR}=0.028), \mathrm{U}=$ $0.00, Z=-3.78,(p=0.00)$. The graph revealed that FLI
TRU-CHROME wires has higher loading force and increased in the area under the curve than the TRUCHROME wires.

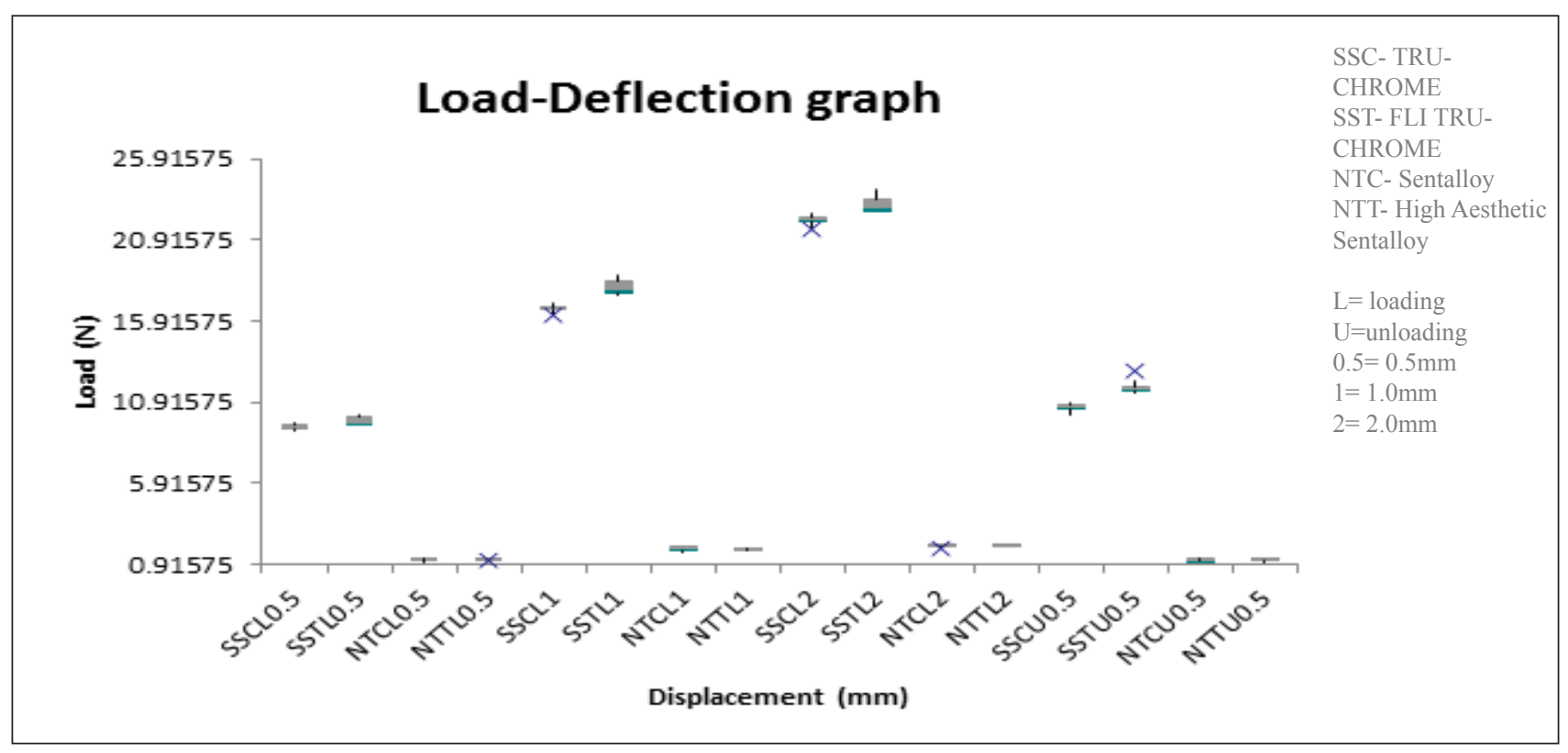

Figure 2: Mean and median force levels of Group I and Group II aesthetic and conventional archwires at different set displacement

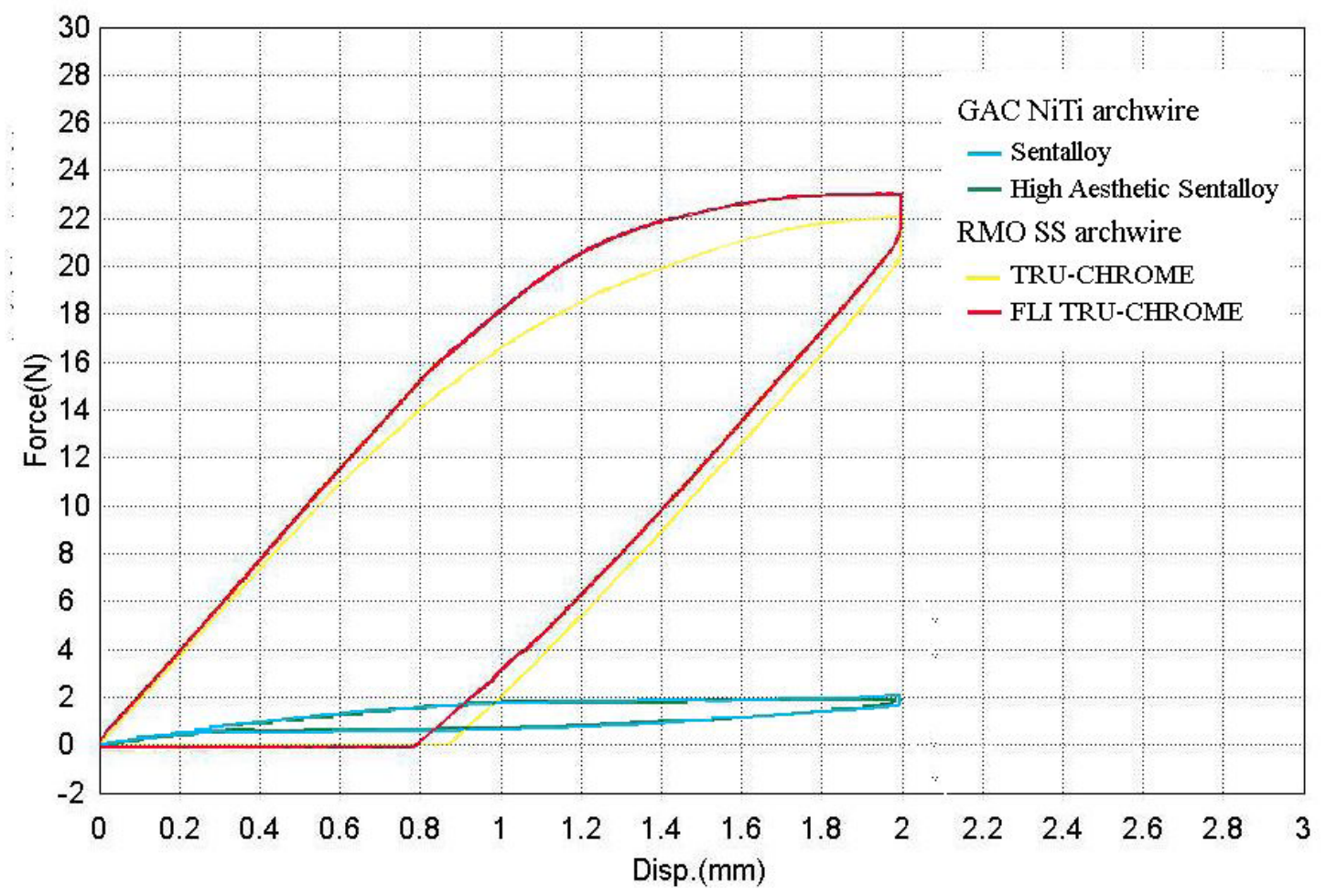

Figure 3: Load-deflection curves of Group I and Group II archwires 


\section{(ii) Indentation Hardness}

There was no significant difference in hardness of the top wire surfaces between test $(M=401.81$, $\mathrm{SD}=14.344)$ and control samples in Group II $(M=412.36, S D=11.746), t(18)=-1.799, p=0.089$. Indentation on the labial surface of FLI TRUCHROME and both surfaces of wires in Group I were not apparent hence were excluded in this section.

\section{(iiia) Average Surface Roughness ( $\mathbf{R a})$}

Group I: GAC Sentalloy and GAC High Aesthetic Sentalloy (NiTi)

The median average surface roughness $(\mathrm{Ra})$ of the all archwires are displayed in Table 3. Non parametric Mann-Whitney test showed that the surface roughness of test group was significantly higher. $U=24.000 Z=-1.965(p=0.049)$.

Group II: RMO TRU-CHROME and RMO FLI TRUCHROME (Stainless Steel)

The median average surface roughness $(\mathrm{Ra})$ were analyzed using Kruskal-Wallis test followed by Mann-Whitney's test as shown in Table 4. Results indicated that coated surface was significantly rougher than both non-coated surface from the same wire. $U=0.000, Z=-3.780 p=0.000$, and control wires. $\mathrm{U}=0.000 \mathrm{Z}=-3.78 \quad(p=0.000)$. However, the non-coated surface of the test wires showed no significant difference in roughness as compared to the control wires. $\mathrm{U}=46.000 \mathrm{Z}=-0.302(p=0.762)$.

Table 4: Roughness (Ra) median $(\mu \mathrm{m})$ and interquartile range of aesthetic and conventional archwires in Group I: GAC High Aesthetic Sentalloy and GAC Sentalloy (NiTi) and Group II: RMO FLI TRU-CHROME and RMO TRU-CHROME (Stainless Steel)

\begin{tabular}{llll}
\hline \multicolumn{1}{c}{ Sample } & \multicolumn{2}{c}{ Aesthetic } & \multicolumn{2}{c}{ Conventional } & Asymp. Sig (2-tailed) \\
\cline { 2 - 3 } & \multicolumn{2}{c}{ Median Roughness $(\mu \mathrm{m})(\mathrm{IQR})$} & $0.049^{*}$ \\
\cline { 1 - 2 } Group I $(\mathrm{Lc}=25 \mu \mathrm{m})$ & $0.1255(0.0230)$ & $0.1160(0.0225)$ & \\
Group II $(\mathrm{Lc}=80 \mu \mathrm{m})$ & Coated surface & $0.1409(0.0287)$ & \\
& $0.4293(0.0359)$ & & Coated surface vs Control $0.000^{*}$ \\
& Non-coated surface & Non-coated surface vs Control 0.762 \\
& $0.1360(0.0290)$ & Coated surface vs Non-coated surface $0.000^{*}$ \\
\hline
\end{tabular}

Values are median and interquartile range in $\mu \mathrm{m}$. (Lc: Lambda $\mathrm{C}$ filter) Significant* $(p<0.0167)$

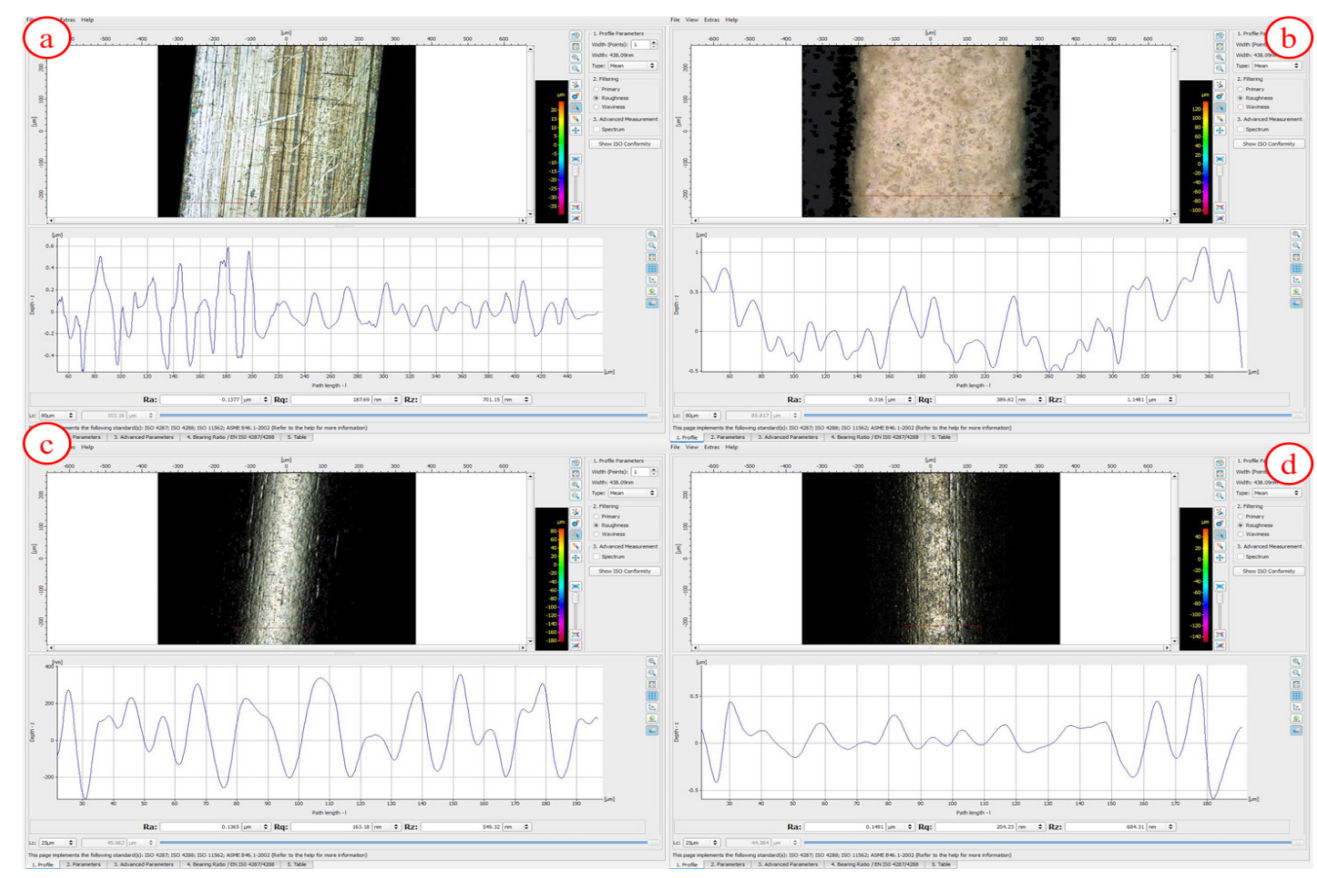

Figure 4: Measuring Ra values using ALICONA. (a) RMO TRU-CHROME (b) RMO FLI TRU-CHROME (labial) (c) GAC Sentalloy (d) GAC High Aesthetic Sentalloy 


\section{(iiib) Surface Topography}

The SEM cross section images revealed the rhodium coating of High Aesthetic Sentalloy wires (Figure 5d) could not be identified. The dimension appears similar to its control (Figure $5 \mathrm{c}$ ). The mean ratio of surface area between Group I archwires have an average of 0.8824 . On the other hand, clear demarcation between PTFE coating layer and the alloy core in Group 3 which affected the dimension of wires (Figure 5b) when compared with control (Figure 5a). The average ratio of surface area between Group II archwires have an average of 1.077 .

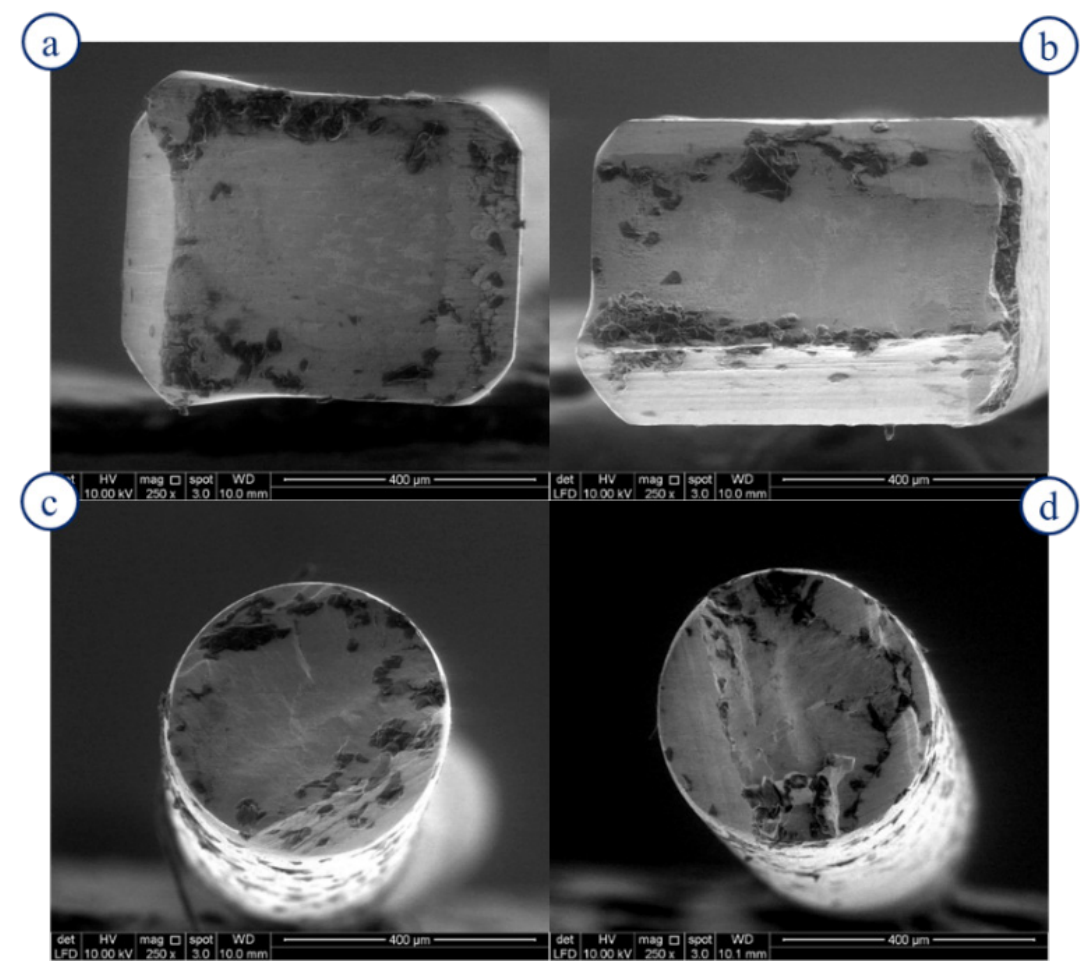

Figure 5: Cross section of archwires [manually cut by the same operator] taken at 250x magnification

a) RMO TRU-CHROME

b) RMO FLI TRU-CHROME

c) GAC Sentalloy

d) GAC High Aesthetic Sentalloy

Surface mircrographs showed that RMO TRUCHROME wires (Figure 6a) are relatively smooth with regular horizontal wire drawing lines. Similarly, the non-coating surface of RMO FLI TRU-CHROME wires are smooth with vertical wire drawing lines (Figure 6b). When captured from labial, it could be seen that the PTFE coating is relatively rough and irregular with non-homogeneous depressions, lumps and voids (Figure 6c). The PTFE and metal interface of RMO FLI TRU-CHROME wires are not regular.
There was excess of coating materials extending from labial surface to the top surface (Figure 6). The Sentalloy control wires (Figure 6e) appears to have partially smooth surface but with slight undulation and pitting. However, the high aesthetic Sentalloy wires presented with homogenous small spherical droplets in addition to the partial undulated surface of the wire (Figure 6d). All before and after load displacement images appeared to be similar with no obvious cracks or defects noted. 


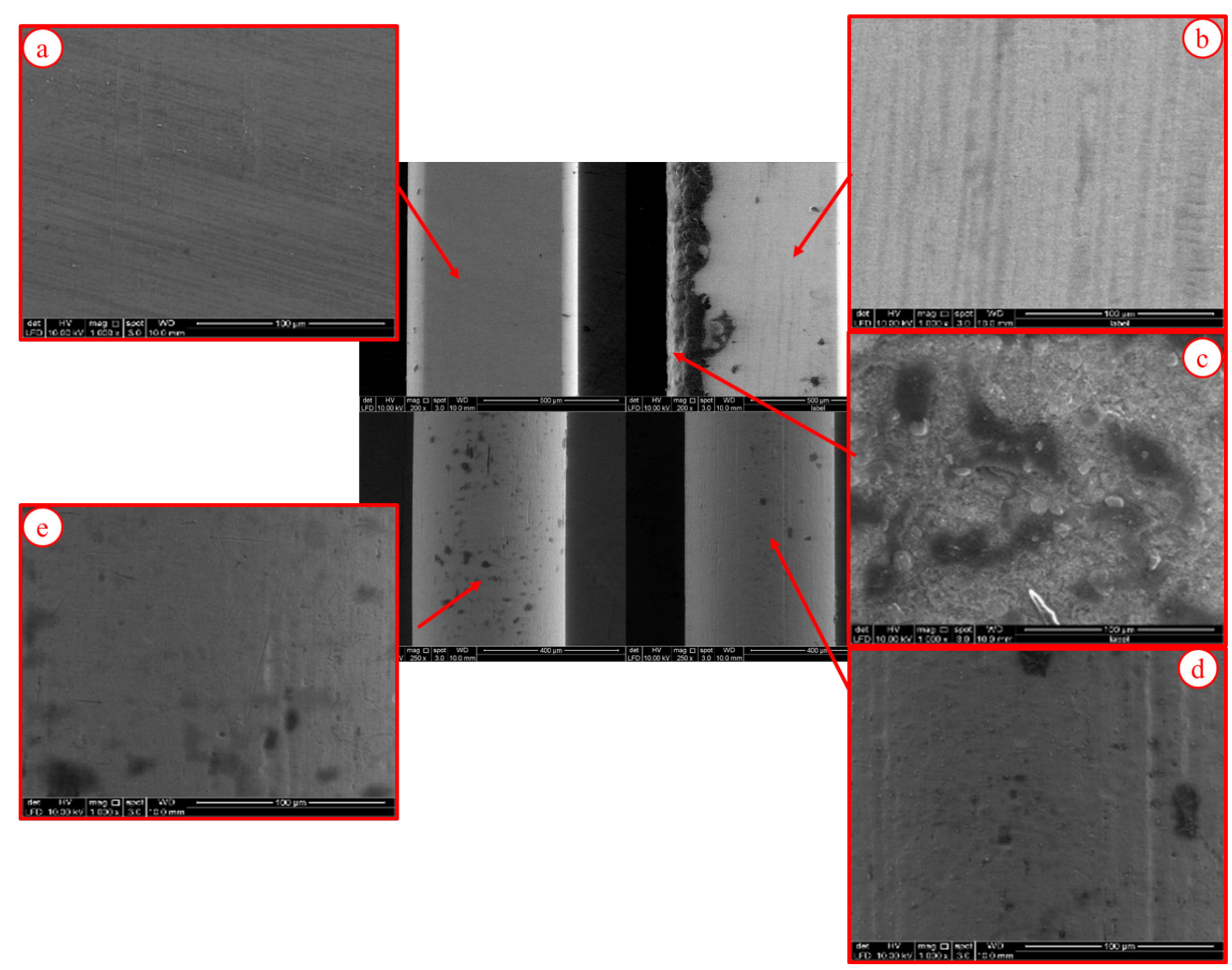

Figure 6: Surface topography of archwires at 200x and 1000x magnification before three point bending. (a) RMO TRUCHROME (b) RMO FLI TRU-CHROME (Top) (c) RMO FLI TRU-CHROME (labial- PTFE coated) (d) GAC Sentalloy Control (e) GAC High Aesthetic Sentalloy

\section{DISCUSSION}

\section{(i) Load deflection}

Three-point bending test was performed due to its ability to closely simulate the clinical applications of archwires and to assess their relative superelasticity (15). Load-deflection diagrams were produced after the test, showing an upper loading curve and a lower unloading curve. The loading curve represent the force required to engage the archwire in bracket slot while the unloading curve indicate the force delivered to the teeth during orthodontic treatment (16). During a fixed appliance mechanotherapy, a clinician will opt for an archwire that produces lower force in initial treatment phase. Typically the wires used are round in cross section hence are loosely engaged in bracket slot but with a drawback of inadequate control of tooth movement. In final treatment phase, a larger and rectangular archwire is chosen for better engagement to bracket and superior control of tooth movement $(1,17)$.

In Group I GAC initial archwires, there was no significant difference of loading and unloading force values between rhodium-coated aesthetic and conventional archwires, suggesting the presence of coating layer did not compromise the load responses of archwire. The similar loading and unloading curves between the test and control samples revealed that the superelastic characteristics of the core nickel titanium wire was not altered by the additional of this this coating layers. This findings is not unexpected as the coating thickness is found to be very thin, approximately $0.5 \mu \mathrm{m}$. This is in agreement with the findings by lijima et al. (11). In addition, both wires exhibited superelastic behavior as they deflected back to the original position with no end displacement. Our finding suggest that this coated archwire could 
be used in initial phase as it maintained the similar springback properties of conventional wires but with more pleasing appearance.

In contrast, the application of coating layer did affect the load-deflection behavior in Group II RMO FLI TRU-CHROME working archwires. The archwire has labial PTFE coating of 0.0001-0.0003 inches $(2.54-7.62 \mu \mathrm{m})$ as claimed by the manufacturer (18). In general, it has significantly higher loading and unloading force values which could be an advantage for working stage where the rigid archwire is required. This finding might be due to the larger cross sectional area of labial-coated archwire as reflected in increased cross sectional surface area ratio measured from SEM images. A small alteration in cross-section dimension could lead to huge changes in load responses (17). Similar finding was reported by Washington et al. who found an increase in mean overall cross-section dimension of archwire when coated PTFE on the labial surface. However, direct comparison cannot be made as they are using different type of wires (10).

It was found that the coating layers remained intact after bending, suggesting the coating is able to withstand certain amount of deflection force without breaking apart. This aspect is important clinically as certain part of the wire might be bent to introduce torque control for final tooth positioning (19).

\section{(ii) Indentation hardness}

The hardness of archwire material is dependent on material strength, proportional limit, ductility, malleability and wear resistance $(20,21)$. There was no significant difference in hardness between TRU-CHROME and uncoated surface of FLI TRUCHROME of Group II. The hardness values of TRU-CHROME wires obtained in this study (412.36 $\pm 11.746 \mathrm{~kg} / \mathrm{mm}^{2}$ ) was similar to that measured by Yu et al. $\left(405.4 \pm 9.9 \mathrm{~kg} / \mathrm{mm}^{2}\right)$ (22). Yet, both of the results were inconsistent with the values reported by Hunt et al. $\left(601.8 \pm 26.9 \mathrm{~kg} / \mathrm{mm}^{2}\right)$. This disagreement is expected as Hunt and co-workers were using $A$. J. Wilcox Australian wires which were produced through a different manufacturing process $(21,22)$.

However, all the hardness values of Group I archwires and Group II coated layer of FLI TRUCHROME surfaces cannot be obtained as the indentation were poorly demarcated. Typically, indentation can be made more visible by polishing the substrate surfaces. Nevertheless, polishing of these coated surfaces rendered impractical as it may wear off the thin rhodium and PTFE coating layers.

\section{(iii) Surface characteristics (roughness and SEM evaluation)}

In this study, surface roughness was investigated as it is directly related to bracket-archwire interface, corrosion potential and rate of tooth movement (23). In clinical orthodontics, it is crucial that least friction between archwire and bracket is introduced to allow free sliding mechanics during treatment $(23,24)$.

In the past various methods have been used to measure surface roughness of orthodontic archwires including contact surface profilometry, atomic force microscopy and laser spectroscopy (23). In our study, 3D non-contact ALICONA system was used to measure the surface roughness. This system has many advantages among others: no restriction on the speed of measurement as the measuring tool does not directly contact with the specimens (25).

It was revealed that High Aesthetic Sentalloy wires were rougher than conventional counterpart. This finding is supported by D'Antò et al. (26) who carried out the surface roughness using atomic force microscope. Our finding also showed that PTFE coating is rougher compared to stainless steel surface. Microscopically, the SEM evaluation corresponds to the average surface roughness measured using ALICONA. It was found that homogenous small spherical droplets were observed on the rhodium coated Sentalloy archwires while non-homogenous irregular lumps were noticed on the PTFE coating. There was no significant difference in surface roughness between non-coated region of FLI TRUCHROME wires and control.

Although the PTFE layer was designed to coat the labial surface, however, excess materials were found on the edges of the top surface which might interrupt the sliding mechanics of the archwire (as apparent in Figure 6). This is supported by Rudge et al. who found that labial coated tooth coloured archwires has increased frictional behaviours (27).

Our SEM micrographs has also revealed that stainless steel (RMO TRU-CHROME control) archwires surfaces were smoother than NiTi (GAC Sentalloy control) archwires surfaces. This finding is supported by Kusy et al. and D'Antò et al. $(26,28)$.

In our study, the wires were tested in dry conditions without any cyclical forces at a relatively constant temperatures. Under this test condition we did not find any difference in SEM evaluation including delamination, cracking and ditching of the coating layers before and after three-point bending test.

This is in contrast with the findings reported by Elayyan et al. who noted delamination, cracking and ditching on PTFE coated archwires after 4-6 
weeks in their ex-vivo study (29). Direct comparison cannot be made as the test condition used were very different. However, this finding need to be interpreted with caution as the materials used were of earlier generation prior to the reformulation of a more durable PTFE layer. Hence, further study to determine the longevity of all types of PTFE coated archwires in simulated oral environment should be carried out.

\section{Limitation of the study}

One of the limitation of the study was that the wires were cut manually by the operator where bending at the edges of the cross section wires were apparent in some samples. This may lead to inaccuracies in cross section surface area measurements (Figure 5).

\section{CONCLUSION}

Within the limitation of this study, the following conclusions can be drawn:

The aesthetic initial archwire (rhodium coated round $\mathrm{NiTi}$ ) has similar load response with its control where it reflected the unaltered characteristic of the core nickel titanium archwire by the coating layer. This characteristic is crucial at the initial stage that requires the flexibility of the archwire. On the other hand, the aesthetic working archwire (PTFE coated rectangular Stainless Steel) has higher load response than its control, which could be an advantage for working stage where a rigid arch wire is required. The heat treatment process of PTFE coating appeared not to have an effect on the hardness of stainless steel wires. However, both aesthetic archwires were found to have increased surface roughness than controls.

Based on our findings, it is suggested that the aesthetic archwires can be used throughout the treatment for selected cases where friction is not critical using rhodium coated NiTi for initial phase and PTFE (labial) coated Stainless Steel for working phase.

\section{Acknowledgement}

The authors would like to thank the research grant fund provided by the Faculty of Dentistry, University of Malaya, Statistician Prof Dr Noorlide Abu Kassim and the laboratory staffs at Biomaterials lab especially Puan Zarina Idris and En. Hassan bin Ismail for all their guidance during the course of the study.

\section{Declaration of Interest}

The authors report no conflicts of interest. The authors alone are responsible with the content of this article.

\section{References:}

1. Juvvadi SR, Kailasam V, Padmanabhan S, Chitharanjan AB. Physical, mechanical, and flexural properties of 3 orthodontic wires: an in-vitro study. Am J Orthod Dentofacial Orthop. 2010; 138(5): 623-630.

2. Quintão CCA, Brunharo IHVP. Orthodontic wires: knowledge ensures clinical optimization. Dental Press J Orthod. 2009; 14: 144-157.

3. Williams J.K., Cook P.A., Isaacson K.G. Thom A.R, Fixed orthodontic appliance: Principles and Practice, Oxford Wright, 1997: Chapter 4 Archwires and accessories: pp. 21-34.

4. Mitchell, Laura. An introduction to Orthodontics. Oxford University Press, 2007: pp 196.

5. Jian F, Lai W, Furness S, Mclntyre GT, et al. Initial arch wires for tooth alignment during orthodontic treatment with fixed appliances. Cochrane Database Syst Rev. 2013 Apr 30;4:CD007859. doi: 10.1002/14651858. CD007859.pub3.

6. Gopal R. Chapter 2 Review of Orthodontic Archwires. 2003. https://scholarbank.nus.edu. sg/bitstream/ handle/10635/13585/07Chapter_2. pdf? sequence $=7$

7. Kravitz ND. Aesthetic archwires: the evolution of aesthetic archwires to meet patient demands for invisible labial treatment. Orthodontic Products. 2013. https://www.rmortho.com/wpcontent/uploads/2013/08/ortho-products-archwire-article-dr-kravitz.pdf

8. da Silva DL, Mattos CT, Sant' Anna EF, Ruellas AC, Elias CN. Cross-section dimensions and mechanical properties of esthetic orthodontic coated archwires. Am J Orthod Dentofacial Orthop. 2013; 143(4): 85-91.

9. Kaphoor AA, Sundareswaran S. Aesthetic nickel titanium wires--how much do they deliver? Eur J Orthod. 2012 Oct; 34(5): 603-9.

10. Washington B, Evans CA, Viana G, et al. Contemporary esthetic nickel-titanium wires: Do they deliver the same forces? Angle Orthod. 2014 Jun 5.

11. lijima M, Muguruma T, Brantley $\mathrm{W}$, et al. Effect of coating on properties of esthetic orthodontic nickel-titanium wires. Angle Orthod. 2012; 82: 319-325.

12. Brantley, W. A. Orthodontic wires. In Brantley, W. A. and T. Eliades . eds. Orthodontic Materials: Scientific and Clinical Aspects. Stuttgart, Germany Thieme. 2001.

13. Ratner, B.D., Hoffman, A.S., Schoen, F.J., \& Lemons, J.E. Biomaterials Science: An 
Introduction to Materials in Medicine: Elsevier Science. 2012.

14. Shackelford, J.F. Introduction to Materials Science for Engineers: Pearson/Prentice Hall. 2005.

15. Krishnan V, Kumar K. Mechanical properties and surface characteristics of three archwire alloys. Angle Orthod. 2004; 74: 825-31.

16. Segner D, Ibe D. Properties of superelastic wires and their relevance to orthodontic treatment. Eur J Orthod. 1995; 17: 395-402.

17. Burstone CJ. Variable-modulus orthodontics. Am J Orthod. 1981; 80: 1-16.

18. FLI® Wire. Rocky Mountain Orthodontics. https://www.rmortho.com/wp-content/ uploads/2011/09/Sales_TechSheets_FLIWire. pdf

19. Ingram SB, Gipe DP, Smith RJ. Comparative range of orthodontic wires. Am J Orthod. 1986; 90: 296-307.

20. Acharya KA, Jayade VP. Metallurgical properties of stainless steel orthodontic archwires: a comparative study. Trends Biomater Artif Organs. 2005; 18: 125-36.

21. Hunt NP, Cunningham SJ, Golden CG, Sheriff M. An investigation into the effects of polishing on surface hardness and corrosion of orthodontic archwires. Angle Orthod. 1999; 69: 433-440.

22. Yu JH, Wu LC, Hsu JT, Chang YY, Huang HH, Huang HL. Surface roughness and topography of four commonly used types of orthodontic archwire. J Med Biol Eng. 2011; 31(5) :367-370.

23. Bourauel CT, Fries T, Drescher D, Plietsch $R$. Surface roughness of orthodontic wires via atomic force microscopy, laser specular reflectance, and profilometry. Eur J Orthod. 1998; 20: 79-92.
24. Wichelhaus A, Geserick M, Hibst R, Sander FG. The effect of surface treatment and clinical use on friction in NiTi orthodontic wires. Dent Mater. 2005; 21: 938-945.

25. Nwaogu UC, Tiedje NS, Hansen HN. A noncontact 3D method to characterize the surface roughness of castings. J Mater Process Tech. 2013 Jan; 213(1): 59-68.

26. D'Antò $V$, Rongo R, Ametrano $G$, Spagnuolo $\mathrm{G}$, et al. Evaluation of surface roughness of orthodontic wires by means of atomic force microscopy. Angle Orthod. 2012; 82(5): 922928.

27. Rudge $P$, Sherriff M, Bister D. A comparison of roughness parameters and friction coefficients of aesthetic archwires. Eur J Orthod. 2014 Aug 1.

28. Kusy RP, Whitley JQ, Mayhew MJ, Buckthal JE. Surface Roughness of Orthodontic Archwires via Laser Spectroscopy. Angle Orthod. 1988 Jan; 58(1): 33-45.

29. Elayyan F, Silikas N, Bearn D. Ex vivo surface and mechanical properties of coated orthodontic archwires. Eur J Orthod. 2008; 30: 661-667.

\section{Corresponding author:}

\section{Associate Prof. Dr. Zamri Radzi,}

Department of Paediatric Dentistry and

Orthodontics,

Faculty of Dentistry,

University of Malaya,

50603, Kuala Lumpur,

Malaysia.

Email: zamrir@um.edu.my

Tel: 03-7967 4802 